\title{
ASSESSMENT OF THE PREVALENCE OF ORAL HABITS IN 3-6 YEAR OLD SCHOOL GOING CHILDREN IN CHANDIGARH AREA
}

\author{
LeenaVerma $^{1}$, Jyoti Gupta ${ }^{2}$, SidhiPassi ${ }^{3}$ \\ ${ }^{1}$ Assistant Professor, Department of Pedodontics, HS Judge Institute of Dental Science, Chandigarh, India \\ ${ }^{2}$ Assistant Professor, Department of Community Dentistry, HS Judge Institute of Dental Science, Chandigarh, India \\ ${ }^{3}$ Assistant Professor, Department of Pedodontic, HS Judge Institute of Dental Science, Chandigarh, India
}

\begin{abstract}
A

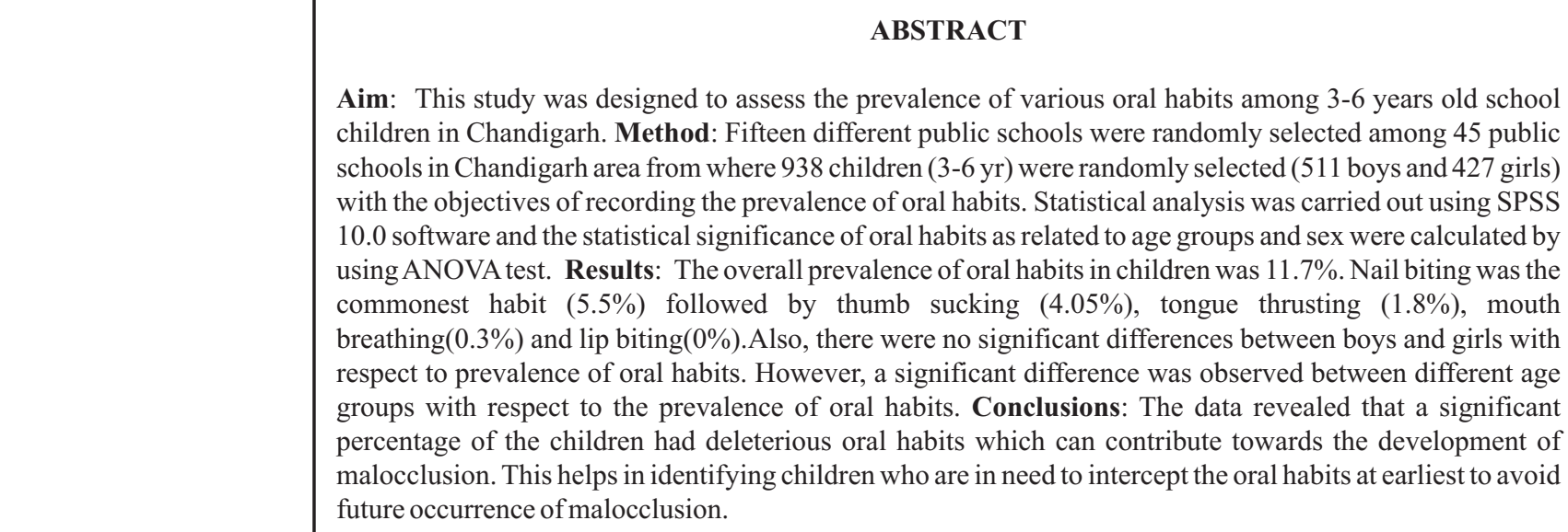

Key words: Malocclusion, Oral Habits, Prevalence, Preventive Orthodontics

\section{INTRODUCTION}

An abnormal habit is a sign of lack of harmony between an individual and his environment. The American Academy of Pediatric Dentistry (AAPD) recognizes that an infant's, child's, or adolescent's well-being can be affected by oral habits creating a need for effective individual management of the same. Oral habits, especially if they persist beyond the preschool age, have been implicated as an important environmental etiological factor associated with the development of malocclusion. ${ }^{1}$ Oral habits are associated with dentoalveolar and/or skeletal

Corresponding Author: Jyoti Gupta E-mail:

jyoti.guptaa@yahoo.co.in Received: $29^{\text {th }}$ April 2016

Accepted: $20^{\text {th }}$ July 2016 Online: $11^{\text {th }}$ September 2016 deformation in some patients. The amount of dentoalveolar skeletal deformation is related to the frequency, duration, direction, and intensity of certain habits and should be assessed by the dentist. Changes that can occur to the dentoalveolar structures may include anterior and or posterior open bite/ or crossbite, interference of normal tooth position and eruption, alteration of bone growth, and cross bites. ${ }^{2}$ A study done by Farsi and Salama in 583 Saudi children aged 3-5 years, selected through stratified cluster sampling technique found the prevalence of sucking habits to be close to $48 \%$ with dummy sucking being the dominant habit. Most dummy suckers were found to have stopped the habit during their earlier years, while digit suckers continued the habit beyond 5 years. The children with a digit sucking habit had a significantly higher prevalence of distal molar and canine 
relationships, larger over jets and open bites compared to children without sucking habits. ${ }^{3}$ Oral habits, if extend beyond the preschool age may cause various types of malocclusions, that in future may require orthodontic intervention. ${ }^{4,5}$ As the duration of the habit increases, the probability of a child developing a class II malocclusion also increases. If the habit was stopped early (before 6 years), the effects on occlusion were often transitory. ${ }^{6}$

There is lack of published data on prevalence of various oral habits in school-going children of Chandigarh in the age range of 3-6 years, the present study was planned to assess the same.

\section{MATERIALS AND METHODS}

A total of 938 children (511 boys and 427 girls) in the age range of 3-6 yrs were selected from 15 different public schools randomly selected from the list of public schools (45 schools) of Chandigarh. The subjects with congenitally missing teeth were excluded from the study. The children with known history of any systemic disease were excluded from the study.

\section{Implementing the study}

Informed parental consent was obtained before commencing the study. Prior to clinical examination, parents were given a questionnaire fill the medical history and history of any oral habit like thumb sucking, nail biting and lip sucking habits and were also informed about the procedure. The selected children were examined by three dentists who were earlier trained to the desired level of consistency. As there was possibility that the children or parents were not aware of tongue thrusting and mouth breathing habits, the children were diagnosed for these habits at the time of examination and only the presence or absence of habit was recorded. Clinical examination was done using mirror and water tests under natural day light.

\section{STATISTICALANALYSIS}

The data analysis was carried out using SPSS 10.0 statistical software. Descriptive statistics including the frequency distribution for males and females,
Percentages of males and females affected with the oral habit, and the prevalence pattern according to different age groups were calculated. ANOVA test was used to calculate inferential statistics and to evaluate statistical significance for oral habits between male and female children and between different age groups. A significance level of $\mathrm{p}<0.05$ was adopted.

\section{RESULTS}

The sample distribution according to age and sex is presented in Table 1. Out of the total 938 children examined, the oral habits were observed in 110 school children, representing an overall prevalence of $11.7 \%$ (Table 2). Nail biting was the most prevalent habit (10.6\%) followed by thumb sucking $(7.7 \%)$, tongue thrusting (3.7\%). Mouth breathing was seen in only 0.5 $\%$ of the children. Lip biting was not seen in any of the children. The percentage prevalence of oral habits was more in males $(14.09 \%)$ as compared to females $(8.9 \%)$.

Table 1: Distribution of children according to age and sex

\begin{tabular}{|l|l|l|l|l|l|}
\hline \multirow{2}{*}{ Age } & Total & \multicolumn{2}{|c|}{ Boys } & \multicolumn{2}{c|}{ Girls } \\
\cline { 2 - 6 } & $\mathbf{N}$ & $\mathbf{N}$ & $\mathbf{\%}$ & $\mathbf{N}$ & $\%$ \\
\hline $3 \mathrm{yrs}$ & 208 & 116 & 55.7 & 92 & 44.2 \\
\hline $4 \mathrm{yrs}$ & 250 & 130 & 52 & 120 & 48 \\
\hline $5 \mathrm{yrs}$ & 210 & 125 & 59.7 & 85 & 40.4 \\
\hline 6 yrs & 270 & 140 & 51.8 & 130 & 48.1 \\
\hline Total & 938 & 511 & & 427 & \\
\hline
\end{tabular}

Table 2: Prevalence of oral habits with respect to sex

\begin{tabular}{|l|l|l|l|l|l|l|}
\hline \multirow{2}{*}{ Variables } & \multicolumn{2}{|l|}{$\begin{array}{l}\text { Total } \\
\text { N=938 }\end{array}$} & \multicolumn{2}{l|}{$\begin{array}{l}\text { Males } \\
\text { N= 511 }\end{array}$} & \multicolumn{2}{l|}{$\begin{array}{l}\text { Females } \\
\text { N=427 }\end{array}$} \\
\cline { 2 - 7 } & $\mathbf{N}$ & $\mathbf{\%}$ & $\mathbf{n}$ & $\mathbf{\%}$ & $\mathbf{n}$ & \% \\
\hline Nail biting & 52 & 5.5 & 40 & 7.8 & 12 & 2.8 \\
\hline Lip biting & 0 & 0 & 0 & 0 & 0 & 0 \\
\hline $\begin{array}{l}\text { Tongue } \\
\text { thrusting }\end{array}$ & 17 & 1.8 & 3 & 0.5 & 14 & 3.2 \\
\hline $\begin{array}{l}\text { Thumb } \\
\text { sucking }\end{array}$ & 38 & 4.05 & 27 & 5.2 & 11 & 2.5 \\
\hline $\begin{array}{l}\text { Mouth } \\
\text { breathing }\end{array}$ & 3 & 0.3 & 2 & 0.3 & 1 & 0.2 \\
\hline Total & 110 & 11.7 & 72 & 14.09 & 38 & 8.9 \\
\hline
\end{tabular}

Prevalence of oral habits in different age groups is shown in Table 3. The prevalence of oral habits in 3 
Vol. 4 (II) 2016 Dental Journal of Advance Studies

Table 3: Prevalence of oral habits with respect to age

\begin{tabular}{|l|l|l|l|l|l|l|l|l|l|l|l|l|}
\hline $\begin{array}{l}\text { Age in } \\
\text { years }\end{array}$ & Total & $\begin{array}{l}\text { Total } \\
\text { \%age }\end{array}$ & \multicolumn{2}{l}{$\begin{array}{l}\text { Thumb } \\
\text { sucking }\end{array}$} & \multicolumn{2}{l|}{$\begin{array}{l}\text { Tongue } \\
\text { thrusting }\end{array}$} & \multicolumn{2}{|l|}{ Nail biting } & \multicolumn{2}{l|}{$\begin{array}{l}\text { Mouth } \\
\text { breathing }\end{array}$} & \multicolumn{2}{l|}{ Lip biting } \\
\hline & $\mathrm{N}=938$ & 11.7 & $\mathrm{n}$ & $\%$ & $\mathrm{~N}$ & $\%$ & $\mathrm{n}$ & $\%$ & $\mathrm{n}$ & $\%$ & $\mathrm{~N}$ & $\%$ \\
\hline 3 & 208 & 17.3 & 18 & 8.6 & 3 & 1.4 & 15 & 7.2 & 0 & 0 & 0 & 0 \\
\hline 4 & 250 & 15.2 & 7 & 2.8 & 0 & 1.6 & 30 & 12 & 1 & 0.4 & 0 & 0 \\
\hline 5 & 210 & 9.5 & 3 & 1.4 & 13 & 6.1 & 3 & 1.4 & 1 & 0.4 & 0 & 0 \\
\hline 6 & 270 & 5.9 & 10 & 3.7 & 1 & 0.3 & 4 & 1.4 & 1 & 0.3 & 0 & 0 \\
\hline
\end{tabular}

Table 4. Frequency distribution ratio according to age and sex

\begin{tabular}{|c|c|c|c|c|c|c|c|c|c|c|c|c|c|c|c|c|c|c|}
\hline & \multicolumn{4}{|c|}{3 years } & \multicolumn{4}{|c|}{4 years } & \multicolumn{4}{|c|}{5 years } & \multicolumn{4}{|c|}{6 years } & \multicolumn{2}{|c|}{ ANOVA } \\
\hline & \multicolumn{2}{|c|}{ Males } & \multicolumn{2}{|c|}{ Female } & \multicolumn{2}{|c|}{ Males } & \multicolumn{2}{|c|}{ Female } & \multicolumn{2}{|c|}{ Males } & \multicolumn{2}{|c|}{ Female } & \multicolumn{2}{|c|}{ Males } & \multicolumn{2}{|c|}{ Female } & \multirow[t]{2}{*}{ F ratio } & \multirow[t]{2}{*}{ Sign. } \\
\hline & $\mathrm{n}$ & $\%$ & $\mathrm{n}$ & $\%$ & $\mathrm{n}$ & $\%$ & $\mathrm{n}$ & $\%$ & $\mathrm{n}$ & $\%$ & $\mathrm{n}$ & $\%$ & $\mathrm{n}$ & $\%$ & $\mathrm{n}$ & $\%$ & & \\
\hline T.S & 10 & 8.6 & 8 & 8.6 & 3 & 2.3 & 4 & 3.3 & 2 & 1.6 & 1 & 1.1 & 4 & 2.8 & 6 & 4.6 & 5.4 & $0.001 *$ \\
\hline T.T & 2 & 1.7 & 1 & 1 & 0 & 0 & 0 & 0 & 6 & 4.8 & 7 & 8.2 & 1 & 0.7 & 0 & 0 & 10.4 & $0.000^{*}$ \\
\hline M.B & 0 & 0 & 0 & 0 & 1 & 0 & 0 & 0 & 0 & 0 & 1 & 1.1 & 1 & 0.7 & 0 & 0 & .2 & 0.826 \\
\hline N.B & 8 & 6.8 & 7 & 7.6 & 20 & 15.3 & 10 & 8.3 & 3 & 2.4 & 0 & 0 & 2 & 1.4 & 2 & 1.5 & 11.9 & $0.000 *$ \\
\hline L.B & 0 & 0 & 0 & 0 & 0 & 0 & 0 & 0 & 0 & 0 & 0 & 0 & 0 & 0 & 0 & 0 & 0 & \\
\hline
\end{tabular}

years old was $17.3 \%$ as compared to $15.2 \%$ in 4 years, $9.5 \%$ in 5 years and $5.9 \%$ in 6 years showing a trend for a decreased prevalence with the advancing age. Table 4 shows the F-ratio for the frequency distribution for age and sex. There was significant difference between different age groups in the prevalence of nail biting, tongue thrusting and thumb sucking habits $(\mathrm{p}<0.05)$. However, there was no significant difference between different age groups in the prevalence of lip biting and mouth breathing. Significant difference in the prevalence of tongue thrusting habit was seen between 4 years and 5 years age groups as well as 5 and 6 years of age group. This difference was also present in nail biting habit in the age groups of 4 years, 5 years and 6 years

\section{DISCUSSION}

The present study reported that $11.7 \%$ of the children examined had oral habit of some or the other kind. Similar kind of studies were done by Shweta jajoo et $\mathrm{al}^{7}$ and Nanda et al8who found out the prevalence of oral habits in school going children of Pune and Luckhnow to be $16.8 \%$ and $17.0 \%$, respectively. In contrast to this study, higher prevalence of oral habits was reported by Quashie-Williams ${ }^{9}$ and Bhavya $\mathrm{DP}^{10}$ who found $34.1 \%$ and $38 \%$ children examined in Lagos (Nigeria) and Gulbarga (India), respectively, presented with an oral habit. Further, Gauba et $\mathrm{al}^{11}$ reported that only 3\% of rural NorthIndian children demonstrated oral habits, which is very much in disagreement with our findings.

Looking into the prevalence patterns of various habits, it was seen that out of $11.7 \%$ the total children affected with some form of oral habits $1.8 \%$ show a tongue thrusting and $5.5 \%$ of them had nail biting habit. Shetty and Munshi ${ }^{12}$ also found a comparatively low prevalence of tongue thrust and a high prevalence of nail biting habit among Mangalore (India) children in the age range of 3-16 years. They observed an incidence of $3.02 \%$ of children as having tongue thrust, which is almost comparable to our study. However, the prevalence of nail biting was $12.7 \%$ according to Shetty et $\mathrm{al}^{12}$ which is not in accordance to the results of this study which shows a prevalence of $5.5 \%$. Our study does not agree with the findings by Gauba et $\mathrm{al}^{11}$ Bhavya et $\mathrm{al}^{10}$ and Kharbanda et al. ${ }^{13}$ where tongue thrusting and mouth breathing habits were the commonest habits. According to Kharbanda et $\mathrm{al}^{13}$ and 
Bhavya et $\mathrm{al}^{10}$ the prevalence of tongue thrusting was almost $18 \%$ which is very high compared to a low of $1.8 \%$ as observed in our study. Differences in the observations of the two studies may be a result of variation in the age group selected. Gauba et $\mathrm{al}^{11}$. selected the age group that was starting from 6-15 years as compared to our study in which the age group was 36 years. However, our findings do agree with the observations of Gauba et $\mathrm{al}^{11}$ that lip biting was the least prevalent habit. In our study, lip biting was not found, but a percentage as high as $6.0 \%$ was observed by Shetty and Munshi. ${ }^{12}$

There existed difference in the prevalence of oral habits at different ages. Oral habits were more prevalent in 3 year old children with $17.3 \%$ prevalence. Whereas least prevalence of 5.9\% was seen in 6 year old children. This difference in age wise prevalence is also reported by Shetty and Munshi. ${ }^{12}$ A steady decrease in oral habits with an increase in age was seen by Quashie and Williams. ${ }^{9}$ The reason for such a decrease with increasing age might be the enhanced perception and awareness which comes with age.

Moreover, the age wise distribution of habits has shown that the most prevalent habit among the 3 years old was thumb sucking (8.6\%) which is considered normal by The American Academy of Pediatric Dentistry (AAPD) ${ }^{14}$ and seconded by Nail biting (7.2\%). Habit prevalent among the 4 years age group was nail biting $(12 \%)$ seconded by thumb sucking $(2.8 \%)$, therefore thumb sucking is regressing with age. The presence of thumb sucking at 4 years and above is cause of concern for the dentist as well as the parent, as child might be under stress or anxiety. Aggarwal et $\mathrm{al}^{15}$ have indirectly related nail biting, thumb sucking etc. to indicate highly stressful and anxiety related behaviors. Surprisingly the dominant habit among 5 years old children is tongue thrusting $(6.1 \%)$ with thumb sucking and nail biting just at $1.4 \%$.

Further, the prevalence of oral habits among male and female school going children has been reported in a study done by Kharbanda et.al ${ }^{13}$ and they stated that thumb sucking was more common in girls than boys and mouth breathing was more common in boys compared to girls. Further Gildasya et $\mathrm{al}^{16}$ and Shweta Jajoo et $\mathrm{al}^{7}$ also showed gender wise difference in the prevalence of the habits, with boys showing slight majority. Our study also showed that the nail biting and thumb sucking habits are more prevalent in males (7.8\% and $5.2 \%$, respectively) as compared to females (2.8\% and $2.5 \%$ respectively). Similar difference was notified by Quashie-Williams ${ }^{9}$ with high prevalence in boys, but the difference was statistically in-significant. These findings could be substantiated with the reason as has been proposed in other studies that probably the oral habits in boys are persistent for longer period than girls because boys are more defiant than girls, including when they are told to stop practicing oral habits ${ }^{17,18,19}$ However, tongue thrusting habit is prevalent among females(3.2\%) as compared to males (0.5\%) showing an increased tendency towards developing mal-occlusion.

\section{CONCLUSIONS}

The following conclusions were drawn from the present study:

1) $11.7 \%$ of school children in Chandigarh areas have some form of oral habit.

2) The Nail biting habit is the commonest oral habit $(10.6 \%)$ followed by thumb sucking $(7.7 \%)$.

3) No lip biting habit was observed.

\section{REFERENCES}

1. Warren JJ, Levy SM, Nowak AJ and Tang S. Non-nutritive sucking behaviours in preschool children: a longitudinal study. Pediatr Dent 2000;22:187-91.

2. Tewari A. Abnormal oral habits: relationship with malocclusion and their influence on anterior teeth. J Indian Dent Assoc 1970; 42: 81-4.

3. Farsi NM and Salama FS. Sucking habits in Saudi children: prevalence, contributing factors and effects on the primary dentition. Pediatr Dent 1997;19:28-33. 
4. Warren JJ, Bishara SE, Steinbock KL, Yonezu T, Nowak AJ. Effects of oral habits duration on dental characteristics in primary dentition. J Am Dent Assoc 2001; 132: 1685 - 93.

5. Khinda V, Grewal N. Relationship of tongue thrust swallowing and anterior open bite with articulation disorders. J Ind Soc of Pedo Prev Dent 1999; 17:33 - 9.

6. William R Proffit. Contemporary orthodontics. 5th ed. St.louis; 2000: 137-44

7. Jajoo S, Chunawala Y, Bijle MN, Shah Roha., KumbleAmol, Gaonkar NK.: Oral Habits in school Going Children of Pune: APrevalence Study. J Int Oral Health 2015;7(10):1-6

8. Nanda RS, Khan I, Anand R: Age Changes in the Occlusal Patterns of Deciduos Dentition. J Dent Res 1973; 52:221-4.

9. Quashie-Williams R, Dacosta OO, Isiekwe MC: The prevalence of oral habits among 4 to 15 year old school children in Lagos. Niger J Health Biomed Sci. 2007; 6(1): 78-82.

10. Bhavya DP, Shyagali TR: Prevalence of Oral Habits in 11-13 year-old School Children in Gulbarga city, India. Virtual J of Ortho 2009;8:1-4.

11. Guaba K, Ashima G, Tewari A, Utreja A: Prevalence of malocclusion and abnormal habits in North Indian rural children. J Indian Soc Pedo Prev Dent 1998;16: 26-30.
12. Shetty SR, Munshi AK: Oral habits in Children - a prevalence study. J Indian Soc Pedo Prev Dent 1998;16: 61-6.

13. Kharbanda OP, Sidhu SS, Sundaram KR, Shukla DK: Oral habits in school going children of Delhi: a prevalence study. J Indian Soc Pedo Prev Dent 2003; 21: 120-4.

14. American Academy of Pediatric Dentistry. American Academy of Pediatric Dentistry Reference Manual 20082009. Pediatr Dent 2008; 30(7) ;51-2.

15. Agrawal M, Ghildiyal R, Khopkar S. Health Status of schoolgirls from affluent population of Mumbai. Indian Pediatr 1999;36:75-8

16. Bandung B, Gildasya, Riyanti E, Hidayat S. Prevalence of oral habits in homeless children under care of Yayasan. Available from:URL: unpad.ac.id/unpad-.

17. Massler M. Oral Habits: Development and Management. JPedodont1983; 7 (2):109-19

18. Polyakov E. Digit sucking before the age 4.5: Interpretation and some management considerations. International pediatrics 2002; 17(4):203-8.

19. Mc Donald RE, DR Avery. Dentistry for the Child and Adolescent. 8th ed. St. Louis: The C.V.Mosby Co; 2004,64651. 